\title{
Benefit of a Second Opinion for Lung Cancer: No Metastasis to the Kidney but a Synchronous Primary Renal Neoplasm
}

\author{
Marleen J. ter Avest ${ }^{a} \quad$ Romane M. Schook ${ }^{a} \quad$ Lyan G. Koudstaal ${ }^{b}$ \\ Katrien Grünberg ${ }^{b}$ Marinus A. Paul ${ }^{c} \quad$ Egbert F. Smit ${ }^{a}$ \\ Pieter E. Postmus ${ }^{a}$ \\ Departments of a ${ }^{a}$ Pulmonary Diseases, ${ }^{b}$ Pathology, and ${ }^{c}$ Cardiothoracic Surgery, \\ VU University Medical Center, Amsterdam, The Netherlands
}

\section{Key Words}

Non-small cell lung cancer - Second opinion - Renal cell carcinoma - Diagnosis/treatment · Metastatic disease $\cdot$ Synchronous primary tumor

\begin{abstract}
Background: The finding of a renal mass on imaging is suggestive of metastatic non-small cell lung cancer in the presence of a lung tumor but can also have another origin. Case Report: We describe the case of a patient diagnosed with stage IV lung cancer based on a renal metastasis. A second opinion including review of histopathological data and additional imaging followed by lung surgery and cryoablation of the kidney lesion revealed two tumors of different origins, non-small cell lung cancer and a renal cell carcinoma. Discussion: The presence of a renal mass diagnosed on a CT scan in a patient with lung cancer is not always synonymous with metastatic disease. Confirmation of diagnosis by tissue sampling is mandatory, especially if a synchronous primary tumor is possible.

(C) 2014 S. Karger AG, Basel
\end{abstract}

\section{Introduction}

The presence of metastatic non-small cell lung cancer (NSCLC) can be suspected by imaging. However, tissue sampling is required to confirm the diagnosis, especially if a synchronous primary tumor is possible. In this case report, we present a case with stage IV lung cancer based on a renal metastasis. 
ter Avest et al.: Benefit of a Second Opinion for Lung Cancer: No Metastasis to the Kidney but a Synchronous Primary Renal Neoplasm

\section{Case Report}

A 48-year-old female received palliative radiotherapy (30 Gy) directed to vertebrae Th9-Th12 and 4 cycles of chemotherapy [gemcitabin $1,200 \mathrm{mg} / \mathrm{m}^{2}$ (on days 1 and 8), carboplatin $80 \mathrm{mg} / \mathrm{m}^{2}$ ] for an 18-FDG-PET avid, thyroid transcription factor-1 (TTF-1) positive adenocarcinoma of the right lower lobe invading the thoracic vertebrae 10 , and an additional 18-FDG-PET negative lesion in the right kidney, cytology-confirmed adenocarcinoma, considered as a distant metastasis (cT4NxM1). Therapy resulted in a slight reduction of both lesions. Due to the determined stage (IV), an expectative approach was opted. The patient initiated a second opinion.

The patient's data were reviewed and additional 18-FDG-PET and CT scans were performed. Except for the presence of the lesion in the kidney, no signs of metastases were found. Therefore, the initial diagnosis was reconsidered as two primary tumors: an adenocarcinoma of the lung, stage IIIB (cT4NOM0) and an adenocarcinoma of the right kidney (cT1a). Two cycles of neo-adjuvant chemotherapy (cisplatinum $80 \mathrm{mg} / \mathrm{m}^{2}$, pemetrexed $500 \mathrm{mg} / \mathrm{m}^{2}$ on days 1 and 21) were administered prior to lung surgery. Surprisingly, no tumor was found in the right lower lobe perioperatively. A hemicorporectomy of Th10 and a resection of the processus transversus of Th10 and Th11 were performed, followed by spine stabilization.

With regard to the lesion of the right kidney, an expectative approach was agreed because of stable disease (no growth), its localization (in the mid pole of the kidney) and small size $(2.3 \mathrm{~cm})$. Eleven months later, cryoablation was ultimately performed because the patient insisted on removal of the tumor, which revealed a papillary renal cell carcinoma. The postoperative course was uneventful. The patient is doing well more than 6 years after the initial diagnosis.

\section{Discussion}

This case report emphasizes the importance of differentiating a primary from metastatic disease when a renal mass is diagnosed on a CT scan in a patient with lung cancer. Although metastases to the kidneys are very uncommon [1], differentiation between these two entities is crucial for further management and prognosis (palliative approach vs. curative intent) [1, 2].

On CT scan, a solitary metastasis to the kidney is more likely to be found in patients with higher tumor stage of the nonrenal malignancy or when other viscera are also affected [1]. Usually, the metastasis is an asymptomatic, small, endophytic, and solid mass [1]. The finding of a corresponding hotspot on FDG-PET scan is suggestive of a metastasis, even if it appears to be benign on CT [3]. However, if the primary tumor is not FGD-avid, this might not be the case. The possibility of a primary renal neoplasm should also be considered, but with caution, since the low sensitivity of detection of FDG-PET scans [3]. Histology obtained by percutaneous biopsy confirms or strengthens the diagnosis in case of small masses and doubts about performing a nephrectomy [4]. If histology alone is not conclusive, immunohistochemistry is useful. TTF-1 is a typical marker for adenocarcinoma in the lung, while negative in primary renal neoplasms, as illustrated in fig. 1 [5].

Once the diagnosis is confirmed, definitive therapy should follow. Patients with localized lung cancers may obtain long-term survival with surgery [2]. In case of a primary renal neoplasm, surgery is the gold standard [6]. 
ter Avest et al.: Benefit of a Second Opinion for Lung Cancer: No Metastasis to the Kidney but a Synchronous Primary Renal Neoplasm

\section{Disclosure Statement}

The authors declare that they have no conflicts of interest.

\section{References}

1 Patel U, Ramachandran N, Halls J, Parthipun A, Slide C: Synchronous renal masses in patients with a nonrenal malignancy: incidence of metastasis to the kidney versus primary renal neoplasia and differentiating features on CT. AJR Am J Roentgenol 2011;197:W680-W686.

-2 Kozower BD, Larner JM, Detterbeck FC, Jones DR: Special treatment issues in non-small cell lung cancer: Diagnosis and management of lung cancer, 3rd ed: American College of Chest Physicians evidence-based clinical practice guidelines. Chest 2013;143(5 suppl):e369S-e399S.

-3 Kaneta T, Hakamatsuka T, Yamada T, Takase K, Sato A, Higano S, et al: FDG PET in solitary metastastic/secondary tumor of the kidney: a report of three cases and a review of the relevant literature. Ann Nucl Med 2006;20:79-82.

4 Sanchez-Ortiz RF, Madsen LT, Bermejo CE, Wen S, Shen Y, Swanson DA, et al: A renal mass in the setting of a nonrenal malignancy: when is a renal tumor biopsy appropriate? Cancer 2004;101:2195-2201.

$\checkmark 5$ Bishop JA, Sharma R, Illei PB: Napsin A and thyroid transcription factor-1 expression in carcinomas of the lung, breast, pancreas, colon, kidney, thyroid, and malignant mesothelioma. Hum Pathol 2010;41:20-25.

$\checkmark 6$ Patel C, Ahmed A, Ellsworth P: Renal cell carcinoma: a reappraisal. Urol Nurs 2012;32:182-190.

Marleen J. ter Avest and Romane M. Schook contributed equally to this case report. 


\section{Case Reports in Oncology}

\begin{tabular}{l|l}
\hline Case Rep Oncol 2014;7:122-125 \\
\hline DOI: $10.1159 / 000359996$ & $\begin{array}{l}\text { C 2014 S. Karger AG, Basel } \\
\text { www.karger.com/cro }\end{array}$ \\
\hline
\end{tabular}

ter Avest et al.: Benefit of a Second Opinion for Lung Cancer: No Metastasis to the Kidney but a Synchronous Primary Renal Neoplasm
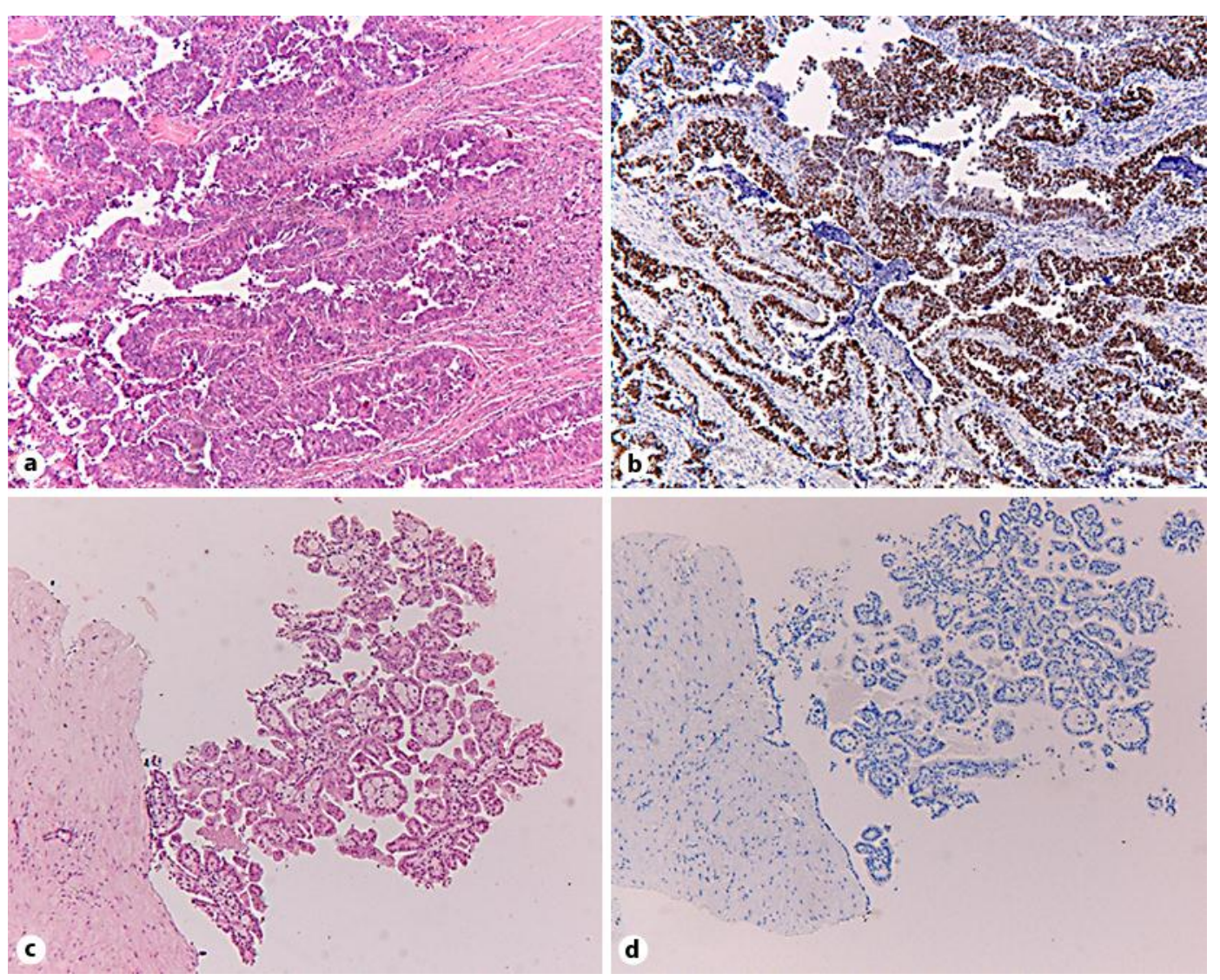

Fig. 1. a Infiltrating glandular structures composed of atypical columnar cells with prominent nucleoli in the resection of thoracic vertebra 10 , histologically consistent with adenocarcinoma of the lung. The papillary growth pattern is less prominent than in the papillary renal cell carcinoma (HE). After therapy, only a small remnant of tumor was found in a background of sclerotic and reactive changes. b Immunohistochemistry for TTF-1 is positive in the adenocarcinoma of thoracic vertebra 10 , consistent with a primary localization of the lung. c Tubulopapillary structures composed of uniform cuboidal cells with unsuspicious round nuclei, without atypia and foamy macrophages in the papillary cores. Histologically consistent with primary papillary renal cell carcinoma type 1 in renal biopsy (HE). d Immunohistochemistry for TTF-1 is negative in the papillary renal cell carcinoma, confirming a second primary tumor. 